\title{
Human Immunodeficiency Virus Infection: Spectrum of Rheumatic Manifestations
}

\author{
Luis E. Vega and Luis R. Espinoza
}

\section{Introduction}

Despite extraordinary advances in diagnostics, therapeutics, and vaccine development, emerging and reemerging viral diseases have occurred during the past several decades $[1,2]$. Several factors that contributed to the emergence of recent epidemics have been identified including those related to the microbial agent, the human host, and the human environment. Also among the most important factors are genetic adaptations of the microbial agent, international travel, human susceptibility to infection, population growth, an aging population, climate and weather changes, and expanding vector habitats [2-5]. Three recent examples of disease emergence are the Middle East Respiratory syndrome coronavirus (MERS-CoV), Chikungunya, and the Zika viruses, which represent new viral entities or viruses emergent in new geographic locales and characterized by novel complications [6, 7]. However, the most important newest example of an emergent infectious disease is human immunodeficiency virus (HIV) infection, which emerged a century ago in a primate host(s), and subsequently spread within the human population. HIV-related acquired immune deficiency syndrome (AIDS), the most dreadful complication, was first recognized in 1981 in men who have sex with men, injection drug users, and recipients of blood transfusions [8-10]. Subsequently, in the year 1983, Francois Barré-Sinoussi, Luc Montagnier, and others from the Institute Pasteur in Paris identified the etiologic agent of this disease and called it the human immunodeficiency virus (HIV). Both French virologists were awarded the Nobel Prize in 2008 for this discovery. At present, however,

L. E. Vega $(\bowtie)$

Department of Medicine, Hospital Central de la Fuerza Aérea, Lima, Peru

L. R. Espinoza

LSU Health Sciences at New Orleans, Louisiana State University, New Orleans, LA, USA
Table 15.1 Differences between HIV 1 and HIV 2

\begin{tabular}{ll|l|l|l} 
Species & Virulence & Infectivity & Prevalence & Inferred origin \\
\hline HIV-1 & High & High & Global & Chimpanzee \\
HIV-2 & Low & Low & West Africa & Sooty Mangabey
\end{tabular}

HIV infection has become a global disease affecting heterosexual individuals, especially within the developing world [11].

The virus HIV belongs to the Retroviridae family and genus lentivirus. There are two serotypes: HIV 1 and HIV 2. HIV1 is the etiologic agent of epidemic AIDS. See some differences between both serotypes (Table 15.1).

\section{Structure}

HIV has a lipid envelope, in which two glycoproteins (gp), the gp41 and gp120, are inserted. These two viral glycoproteins are responsible for attachment to the host cell. Beneath the envelope, is the matrix p17, the core proteins p24 and p6 and the nucleocapsid protein p7. Within the viral core lie two copies of the viral ribonucleic acid (RNA) genome, together with the protease, integrase, and reverse transcriptase enzymes (Fig. 15.1). All of these structures are codified by different viral genes.

\section{Life Cycle}

Once the human immunodeficiency virus enters in the body of a human being, it binds to its specific receptor. The HIV virus attaches to the CD4 receptor which is present on the surface of the CD4+ T cell and then either a CCR5 or CXCR4 co-receptor, to replicate itself and infect other cells. After binding to the CD4+ receptor the virus uses the machinery of the CD4+ T cell, to replicate and spread throughout the body. The process of replication is carried out in several stages: binding, fusion, reverse transcription, integration, replication, assembly, and budding. 


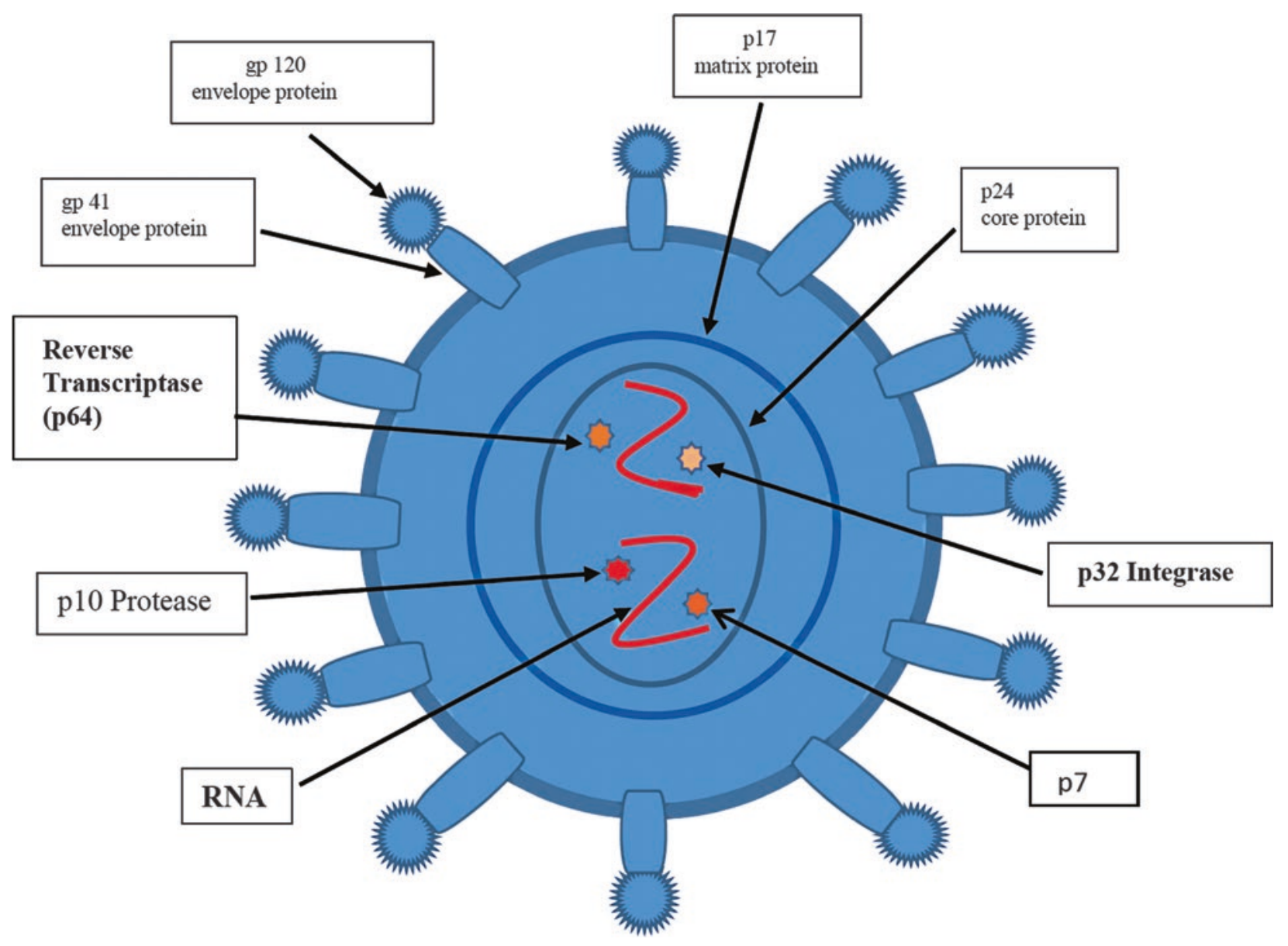

Fig. 15.1 Structure of HIV

\section{Pathogenesis}

Pathogenesis of HIV infection is complex, multifactorial, and incompletely understood. HIV infection's main target is the resting memory CD4 $+\mathrm{T}$ cell and selective depletion of CD4 $+\mathrm{T}$ cells is accompanied by aberrant activation of all the components of the immune system [12]. Immune activation is the major force that drives the HIV process and is associated with viremia and has a negative correlation with the CD4+ T cell count during chronic infection [13]. Cellular and soluble factors play an important role in acute and chronic immune activation and progression to AIDS [12-14] (Table 15.2 and Fig. 15.2).

\section{Autoimmunity and HIV}

The combination of immune dysfunction in patients with HIV infection and the development of autoimmune diseases is still incompletely understood. Autoantibodies are found with high prevalence in sera from HIV patients and may be fostered by a polyclonal stimulation of B cells.

\section{Autoantibodies in HIV}

- Anti- $\alpha$-myosin

- Anti-EPO

- Anti-TPO

- Anti TSHR

- Anti-cardiolipin

- Anti-PS

- Anti-PI

- Anti-PC

- Anti- $\beta 2$ GPI

- Anti-prothrombin

- Anti-DNA

- Anti-RNP

- Anti-GBM

- ANCA

$E P O$ erythropoietin, $T P O$ thyroid peroxidase, $T S H R$ thyroid stimulating hormone receptor, $P S$ phosphatidylserine, $P I$ phosphatidylinositol, $P C$ phosphatidylcholine, $\beta 2 G P I$ Beta 2 glicoproteína, GBM glomerular basal membrane. 
Table 15.2 Cellular and soluble factors in immune activation

\section{Innate}

Cells Activation of macrophages and dendritic cells

Cytokines, chemokines

Acute phase proteins

Coagulation

Fibrosis

Microbial sensors

Adaptive

$\mathrm{T}$ cells formation of autoreactive CD8+, depletion Treg cell

B cells
Increased turnover CD4+ and CD8+, CD4+ decrease, CD8+ increase and then decreases,

TNF $\alpha$, IL-1, IL-6, IL-8, IL-12, IL-15, CXCL10, INF $\alpha$

Serum amyloide $\mathrm{A}, \mathrm{C}$ reactive protein

D-dimers, tissue factor

Activation of matrix metalloprotease, collagen deposition

Lipopolysaccharide binding protein, soluble CD14 Hyperactivation, hypergammaglobulinemia and immune complexes, autoantibodies
The presence of autoantibodies is associated with lower CD4+ T cell counts and increased mortality, which implies prognostic significance to this phenomenon in the context of HIV infection [15]. HIV immune dysregulation involving $\mathrm{T}$ or B cells or both may lead to autoimmune phenomena unique to HIV disease or to more classic autoimmune clinical syndromes.

Several possible mechanisms for autoimmune manifestations of HIV infection have been described, but molecular mimicry appears to be one of the most relevant. HIV virus has molecular similarity to self-antigens and may, therefore, induce antibody cross-reactions and lead to the development of autoimmune disease [16-18]. Whether autoimmunity is a component of natural immunity to HIV, its clinical significance and the role of neutralizing antibodies remain to be defined $[16,18]$.
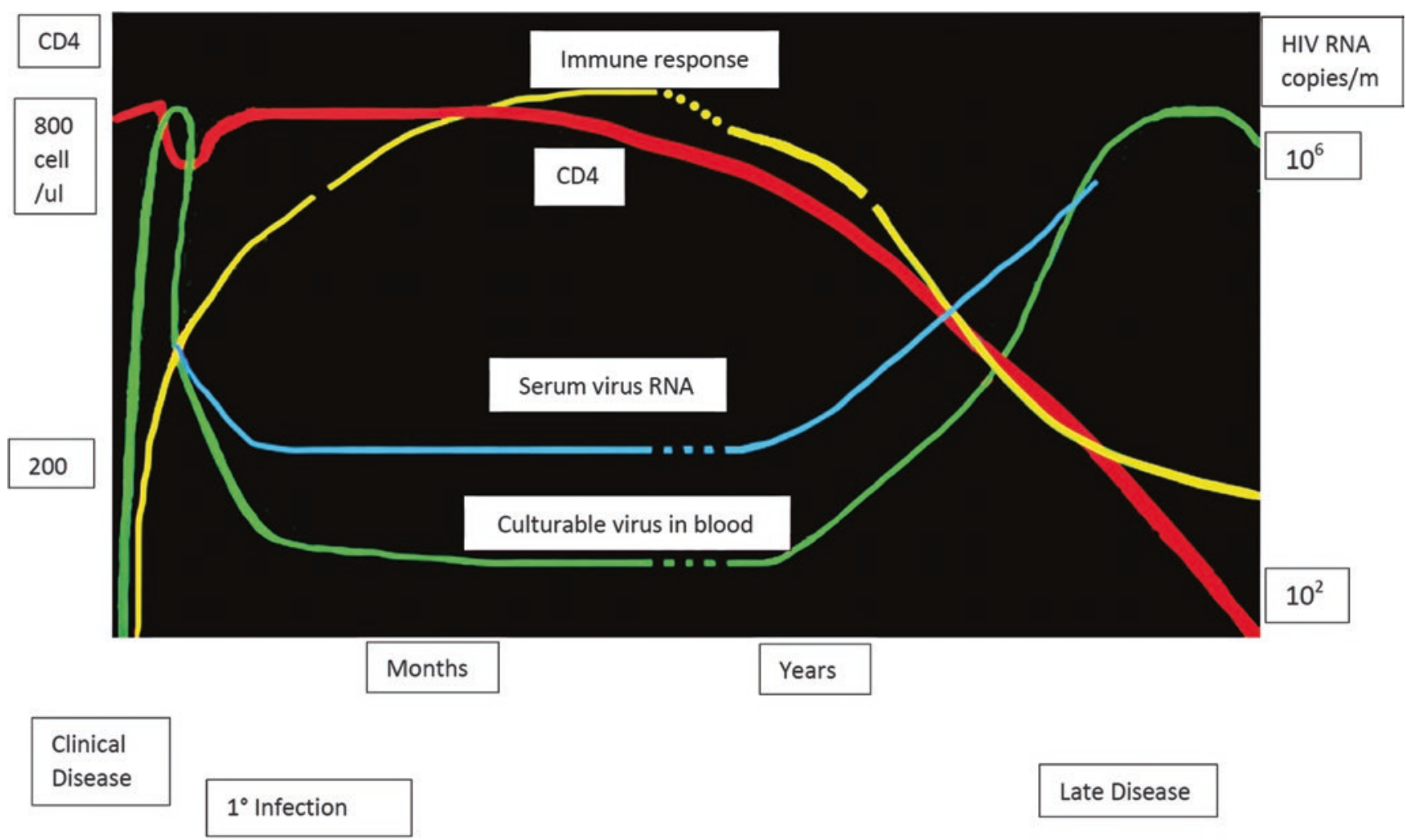

Late Disease

Immune activation markers

\begin{tabular}{|l|c|c|c|c|c|c|}
\hline TNF $\alpha$ & +++ & + & + & + & ++ & +++ \\
\hline IL-6 & +++ & $-/+$ & $-/+$ & + & ++ & +++ \\
\hline SIL-2R & +++ & $-/+$ & $-/+$ & + & ++ & +++ \\
\hline CD8-HLA-DR & +++ & + & + & + & ++ & +++ \\
\hline CD8-CD38 & +++ & + & + & + & ++ & +++ \\
\hline
\end{tabular}

Fig. 15.2 Natural course and immune activation markers of HIV 


\section{Autoimmune Mechanisms HIV}

1. Direct effect of HIV: endothelial, synovial, hematopoietic cells

2. Increase cytotoxic cell activity

3. Increased expression of autoantigens

4. Molecular mimicry

Close to 40 years have elapsed since the onset of the HIV/AIDS pandemic and a total of 36.7 million individuals are living with the infection in 2016, including 1.8 million newly infected individuals, 1.0 million deaths, which includes 890,000 adults and 120,000 children under the age of 15 years, and 20.9 million living with HIV on antiretroviral therapy in 2017 [19]. Extraordinary progress in our understanding of pathogenesis, natural course, diagnostics, and combination antiretroviral therapy (cART) has occurred, which has led to a significant improvement in morbidity and mortality [20]. To date, the status of a considerable proportion of HIV/AIDS patients has changed from a near-fatal disorder secondary to opportunistic infections to a chronic disease in which cardiovascular, renal, diabetes, malignancy, and autoimmune co-morbid disorders have become prevalent and relevant [21-23]. The latter makes this topic of great relevance and importance to clinicians including rheumatologists and other practitioners dealing with this condition.

There are only a few longitudinal, descriptive, and comparative studies that allow with certainty define the impact of HIV infection during the pre-cART and post-cART eras, however, we will review and discuss available data on HIV infection and rheumatic manifestations.

\section{Prevalence of Rheumatic Manifestations Before the Advent of cART Therapy}

Winchester et al. first reported the association between HIV and rheumatic disease in 1987, when they described a series of patients with AIDS and Reiter's disease. Since that time, several reports have been published [24], and the prevalence of rheumatic manifestations among HIV infected patients ranges from $3 \%$ to $71 \%$ [25-29].

Arthralgia is the most common complaint, usually intermittent and polyarticular, with a reported prevalence between $1 \%$ and 79\% [30]. Myalgia has also been frequently reported and difficult to separate from myopathy, so that the estimated prevalence rates may be misleading. Results of case-control studies revealed that myalgia is more common in HIV infected than in uninfected controls, with a frequency of $1.7-11 \%$ in the pre-cART while it increased between $0 \%$ and $77 \%$ in the post-cART. There are, however, other studies that showed the opposite; therefore, it is not clear whether therapy improves or exacerbates myalgia [31].

\section{Painful Articular Syndrome}

This syndrome is characterized by an acute onset and severe intensity of arthralgia presenting typically in one (usually large) joint in HIV-positive patients. It is of short duration (2-24 hours) and not associated with synovitis. It has an estimated prevalence of $10 \%$ among US patients in the late stages of the infection $[26,32]$ and a similar rate was observed among patients in Argentina [27]. This syndrome has not been reported in other case series from Africa and Asia continents [33-36]. The effect of cART on this syndrome is currently not well-defined.

\section{HIV Arthritis}

This syndrome is characterized by an acute onset of arthritis of large joints, non-erosive, lasting less than 6 weeks, absence of HLA B27 positivity and radiological changes, distinct from any other known rheumatic disease, with no known infective triggers, or other classical features. The prevalence rate ranges from $0.4 \%$ to $13.8 \%$ and most of these studies were performed in the USA. Most reports demonstrate that most cases occur in men, most commonly in the CDC stage IV of HIV infection [26, 27, 33, 37-42]. There is a cohort study from Africa where the reported prevalence was $82 \%$ [43]. Other African studies have not reported such high prevalence rates [44, 45].

\section{Spondyloarthritis}

\section{Reactive Arthritis (ReA)}

Most cases of $\operatorname{ReA}$ are associated with the late stages of immunosuppression seen in HIV-infected patients. The estimated prevalence of $\mathrm{ReA}$ in the pre-cART was as low as $0.02 \%$ to a high of $11 \%$, variability depending on the sample studied. In the USA, two cohort studies performed through questionnaires, San Francisco Men's Health Study and the Johns Hopkins Multicenter AIDS Cohort Study, did not find an increase in ReA. However, most patients studied were in the early phase of HIV-infection [30, 31, 46].

In Latin American countries such as Mexico and Argentina, the frequency of ReA was found increased, while in Spain it was low. Mode of transmission appeared to explain the difference, with sexually-transmitted in Mexico and Argentina, and intravenous drug use in Spain [27, 38, $39,47]$. The low frequency of $\operatorname{ReA}$ has been reported in other cohorts in whom the mode of transmission was IV drug use [48].

Of great interest is the situation in Africa in which prior to the HIV pandemic ReA was rarely seen, which might be explained on the basis of the rarity of HLA-B27 [49, 50]. Following the advent of HIV, however, ReA became a com- 
mon occurrence among HIV infected individuals with the majority being HLA-B27 negative [44]. Epidemiological studies in Zambia revealed that the presence of the allele HLA-B $* 57: 03$ confers a protective effect against the rapid progression of HIV [51].

Studies from Asian countries point out that ReA in HIV patients rarely occurs [36]. In this regard, mode of transmission of HIV appears to be similar in Asia and Africa, heterosexual, with a high prevalence of arthritogenic pathogens, which might suggest that other factors including genetics might play a role.

It can be concluded that ReA was relatively common in the western world pre-cART and its prevalence greatly diminished in the post-cART.

\section{Psoriatic Arthritis (PsA)}

A similar situation as in ReA occurs with PsA in which several studies on the pre-cART era revealed an increase in afflicted HIV infected patients. Rates of prevalence for PsA in HIV patients pre-cART was higher than in the general population, $0.4-5.7 \%$ vs. $0.25 \%$, respectively $[40,52]$ and rates of incidence similar in both populations, $0.07 \%$ /annum vs. $0.05 \%[30,46]$. The populations studied, however, were in different stages of HIV infection. It should also be noted that patients with HIV and psoriasis had more severe and persistent lesions, and when compared with patients with classic psoriasis in HIV several morphological types can coexist in the same patient and that PsA was severe, deforming, erosive, and refractory to conventional therapy [53, 54].

The incidence and prevalence of both psoriasis and PsA in Africa are low even though black Africans have one of the risk alleles for psoriasis, HLA-CW6. This, however, drastically changed following the advent of HIV in which both disorders were increasingly recognized in African populations [55, 56]. Asian populations have a low prevalence rate of psoriasis and PsA, but this also changed following the HIV pandemic. Post-cART, both disorders have greatly diminished in Africa and Asia.

\section{Ankylosing Spondylitis (AS)}

AS, the prototype of the spondyloarthritides, is more common in the western world [57] and much less common among sub-Saharan Africans where the frequency of HLAB27 is very low $(<1 \%)$. The frequency, however, of HLAB27 in West Africa is higher 7.8-9.7\% [58, 59], but despite this higher prevalence AS is rarely seen in this region. This, however, changed following the onset of HIV in which several reports describing the association were reported from African populations.

In general, there have been few reports of AS in HIV infected patients and reported data might suggest that AS is uncommon in HIV. But it is probable that most patients with HIV or AIDS are classified as having undifferentiated spondyloarthritis in the absence of radiographic or HLA-B27 testing or the paucity of long-term follow-up studies.

\section{Rheumatoid Arthritis (RA)}

The immune dysregulation inherent to HIV infection and its clinical manifestations may mimic or interfere with a diagnosis of rheumatoid arthritis. HIV patients may exhibit symmetrical polyarthritis, which tends to be seronegative for the most part. However, erosive forms and seropositive for rheumatoid factor (RF) have also been described [60]. On the other hand, the presence of low titer RF and CCP antibodies in patients with HIV may lead to an erroneous diagnosis of RA. HIV patients may also exhibit a high proportion of RF and CCP antibodies, which decrease after initiation of cART suggesting that HIV is capable of inducing autoantibodies. Follow-up studies, however, of this HIV population does not reveal the development of RA [61-64]. In addition, it is well recognized the presence of false-positive HIV serology in patients with RA suggesting a cross-reactivity between HIV diagnostic tests in patients with RA [65]. Another important issue was the impact of de novo HIV infection in established RA $[66,67]$. An early observation in the pandemic was that most RA patients might go into remission after the development of AIDS. However, the presence of active RA disease including radiological progression can be seen despite a profound state of immunosuppression [68, 69]. Also, development of de novo RF and CCP antibodies positive RA can be seen in well control HIV infection (normal CD4 cell count and negative HIV viral load), and RA disease activity behaves in identical fashion as in RA seen in HIV negative individuals.

Therapy for HIV patients affected with RA as well as for most connective tissue disorders is not well defined, but most can be safely treated in identical manner as in the non-HIV afflicted population. Caution, however, and prophylaxis for opportunistic infections, should be exerted when immunosuppressive or biologic therapy is used.

\section{Systemic Lupus Erythematosus (SLE)}

SLE has been rarely reported in association with HIV infection, but it represents a diagnostic and therapeutic challenge, especially when they co-exist in the same patient. HIV impacts on SLE in diagnosis and assessment of disease activity. HIV infection and SLE shares several clinical features and laboratory findings, which can make the diagnosis extremely difficult. A variety of constitutional manifestations such as fever, arthralgia, arthritis, myalgia, skin rash, lymph node enlargement, cytopenias, pulmonary, cardiovascular, renal, and CNS involvement can be observed in both active 
SLE and HIV infection. A variety of autoantibodies including ANA, anti-dsDNA, anti-Sm, and anti-cardiolipin antibodies can be seen in both disorders. But hypocomplementemia secondary to HIV has not been described, and this finding may be used to distinguish lupus activity from HIV infection [70, 71]. Diagnostic tests for HIV have been reported as false-positive results in SLE patients and multiple studies have reported autoantibodies reactivity to HIV p18 and p24 antigens. These findings make necessary the need to perform confirmatory tests, such as viral RNA PCR or HIV-Western Blot assays [72].

HIV infection, as described in RA, may have an important effect on the natural course of SLE. The decrease in CD4 lymphocytes might ameliorate SLE disease activity and induce remission. However, SLE disease activity may persist during HIV infection and not related to the use of cART [73-75].

Lupus may also impact on HIV infection. Homology between self-antigens in lupus patients and viral proteins has been identified. Antibody production including neutralizing antibodies might develop during SLE may confer protection against HIV infection by molecular mimicry mechanisms [76]. In addition, antimalarial drugs such as chloroquine and its derivatives, which are used in SLE therapy, may have anti-HIV activity. A potential role for interleukin-16 in the observed low incidence of HIV infection in patients with SLE has been described [77].

Treatment of SLE with glucocorticoids and immunosuppressive drugs is challenging because they may trigger viral replication and rapid progression of the disease. On the other hand, the use of cyclophosphamide in lupus flares may also result in an increase in the viral load. Viral load becomes undetectable when cyclophosphamide is discontinued. Therefore, treatment of active lupus should be individualized and should be aimed at reaching a balance between HIV infection and lupus activity.

The association of HIV-related discoid lupus and HIV has rarely been reported and the few cases described have occurred after the onset of cART and in association with undetectable HIV viral load and normal CD4 T-cell count [78].

\section{Anti-Phospholipid Antibody Syndrome (APS)}

Presence of anti-phospholipid antibodies including anticardiolipin and lupus anticoagulant antibodies is seen in most HIV patients, 60-70\%. However, the development of clinical manifestations characteristic of APS is uncommon, and only a handful of cases have been reported in the literature. Other anti-phospholipid antibodies such as anti-B2 Glycoprotein I appear to have a lower frequency [31, 79].

\section{Systemic Sclerosis (SSc)}

The association between HIV infection and SSc is rare. There are only a few reported cases. Two male patients developed localized scleroderma after several years of cART. Two other patients developed symptoms of diffuse systemic sclerosis. One of the two cases in the background of immunosuppression and responded well to therapy with steroids and cART. The other patient developed symptoms of SSc 7 years after HIV infection and cART and with good virologic suppression and normal CD4 cell count [80-82].

\section{Polymyositis and Dermatomyositis}

These diseases have rarely been reported. The prevalence of polymyositis is reported as $0.22 \%$ and dermatomyositis occurs less frequently, and when present can occur at any stage of HIV infection. HIV-associated polymyositis usually has mild disease activity, which is often difficult to recognize, especially in a population that frequently manifests generalized weakness and a debilitating course. Both polymyositis and dermatomyositis carry a relatively good prognosis, responds well to glucocorticoids and immunosuppressive therapy $[83,84]$.

\section{Diffuse Infiltrative Lymphocytosis Syndrome (DILS)}

DILS was initially identified in 1985 as lymph node hyperplasia and parotid gland enlargement in HIV-positive patients. Later, in 1989, this complex was named "diffuse infiltrative lymphocytosis syndrome". Early criteria proposed by Itescu et al. for the diagnosis of DILS required salivary gland enlargement or xerostomia for $>6$ months and lymphocytic infiltration of the affected gland confirmed by biopsy [85].

Diagnostic Criteria for DILS (Itescu et al. [85])

Requires All Criteria

1. HIV infection (positive serology)

2. Bilateral salivary gland enlargement or xerostomia

3. Persistence of signs/symptoms for 6 months or more

4. Histologic confirmation of salivary or lacrimal gland lymphocytic infiltration without granulomatosis or neoplastic involvement 
Table 15.3 Features of DILS

\begin{tabular}{|c|c|}
\hline Feature & \\
\hline Lymphocytic infiltration & CD8+ T cells \\
\hline Sicca symptoms & Present \\
\hline $\begin{array}{l}\text { Glandular } \\
\text { manifestations }\end{array}$ & Moderate to severe parotid enlargement \\
\hline $\begin{array}{l}\text { Extra-glandular } \\
\text { manifestations }\end{array}$ & Present \\
\hline Autoantibodies & $\begin{array}{l}\text { Rarely present, exceptional low frequency } \\
\text { of RF, ANA, anti-Ro }\end{array}$ \\
\hline HLA association & DR5(DR11), DR6(DR13), B45, B49, B50 \\
\hline
\end{tabular}

HIV-related DILS is characterized by salivary and lacrimal glandular swelling and sicca symptoms of varying intensity. Prevalence of this complication is highest among African Americans (up to $48 \%$ of infected individuals) and is associated with HLA class II alleles (DRB1) that are not seen in other racial groups with DILS, and it occurs in patients whose disease is at less advanced stages [86, 87]. The syndrome usually presents as a Sjögren-like illness that generally associates with sicca signs with bilateral parotid gland swelling, lymphadenopathy, and extra-glandular organ involvement. DILS is also characterized by CD8+ T cell infiltration, lack of autoantibodies (anti-Ro and anti-La), although they may be present in some exceptions, and extra-glandular visceral infiltration. The lung, being the most common extra-glandular organ involved and when affected it presents as a lymphocytic interstitial pneumonitis (LIP)[86, 88]. Its natural history has also changed since the introduction of cART, and it is less frequently seen including the extra-glandular manifestations such as LIP $[87,89]$.

Chen et al. conducted a nationwide population-based study in the Taiwanese population and showed that the incident rate of DILS was 0.56/1000 person-years higher compared with the general population, and the incidence was higher in patients without cART than in patients with cART, supporting the notion that HIV intervenes in the pathogenesis of DILS and that cART reduces the risk of acquiring DILS $[90,91]$. Other clinical and laboratory features of DILS are shown in Table 15.3.

DILS patients with mild symptoms may not require specific treatment, but glucocorticoids or immunosuppressive drugs should be considered for patients with progressive glandular involvement.

\section{Vasculitis}

The entire clinical spectrum and size of involved blood vessels can be seen in HIV-associated vasculitides. The incidence of vasculitis in HIV infection is relatively low at $1 \%$. Its presence, however, varies according to ethnic origin and it appears to have a higher prevalence in Orientals. Vasculitis has been reported
Table 15.4 Features of HIV-PAN

\begin{tabular}{|c|c|}
\hline Feature & \\
\hline Virus-associated & No associated HBV \\
\hline Involvement & Rare multisystem \\
\hline $\begin{array}{l}\text { Common } \\
\text { symptoms }\end{array}$ & Peripheral neuropathy, rash \\
\hline Clinical course & $\begin{array}{l}\text { Usually not progressive or fulminant, } \\
\text { nonlife-threatening }\end{array}$ \\
\hline
\end{tabular}

in patients infected with HIV more commonly in those with a profound stage of immunosuppression $(C D 4+<200 / \mu l)$, in some associated with hepatitis B infection, but has also been reported in early HIV stages $(>500 \mu \mathrm{l})[92,93]$.

As it has been described with other rheumatic manifestations, factors such as ethnic origin and route of transmission might be implicated in its prevalence. Zhang et al. have reported a high prevalence of vasculitis when compared to other rheumatic syndromes. They reported 20 cases of vasculitis in a cohort of 98 Chinese patients and the main route of transmission in their population was blood transfusion. A variety of syndromes were reported including Behçet-like disease, Henoch-Schonlein purpura, digital gangrene, and central nervous system vasculitis [36].

Polyarteritis nodosa (PAN) is the most prevalent form of vasculitis coexistent with HIV infection, and it is not related to hepatitis B infection like the classic form, and can occur at any stage of HIV disease. The clinical course of HIV-related PAN exhibits major differences in comparison with classic HBV-related and it is clinically less aggressive, and peripheral neuropathy is the most common clinical manifestation [94, 95] (Table 15.4).

Presence of anti-neutrophil cytoplasmic antibodies, especially pANCA, is high (13-42\%), but its clinical significance is not well defined. cART plays a beneficial role in its treatment due to a direct role of HIV in the pathogenesis of PAN. On the other hand, the impact of other viruses including hepatitis $\mathrm{B}$, hepatitis $\mathrm{C}$, cytomegalovirus (CMV), Epstein-Barr (EBV), and varicella-zoster virus (VZV), which often coexist in HIV positive individuals is not fully characterized [23, 94, 96].

Glucocorticoids have been successfully used in many cases of HIV-associated vasculitis and immunosuppressive drugs should be reserved for resistant patients.

Other forms of vasculitis such as Henoch-Schonlein purpura might occur secondary to various infectious triggers. ANCA-associated vasculitis is extremely rare in HIV infected patients [23].

Cryoglobulinemia may coexist with HIV infection. Its presence is usually asymptomatic and responds well to cART regimen [86]. In the cART era, HIV-infected patients have been shown to have decreased levels of serum cryoglobulins $[95,97,98]$. 


\section{Septic Arthritis}

Osteoarticular infection due to pyogenic bacterial does not occur more frequently in patients with HIV infection as compared with the general population. The incidence of musculoskeletal infections in patients with HIV appears to be low $(0.3-3.5 \%)$. Case series reported from the USA, Europe (Italy), and Africa have shown that septic arthritis occurs less frequently in HIV patients [99-101]. There are retrospective HIV cohort studies that show a relatively low risk of septic arthritis [102, 103]. Marquez et al. studied prospectively 75 patients with HIV infection referred to a rheumatology clinic in New Orleans and reported prevalence of septic arthritis and osteomyelitis in $8 \%$ and $20 \%$, respectively. Atypical mycobacterial (mycobacterium haemophilum and Kansasii) and fungal (candida and sporotrichosis schenckii) infections rarely occur except in advanced HIV infection (CD4 count less than $100 / \mathrm{mL}$ ).

\section{Rheumatic Disorders in the Combination Antiretroviral Therapy (CART): Future Trends}

Introduction of cART in the management of patients infected with HIV marks a milestone in the history of medicine because it led to a significant change of the natural history, long-term outcome, occurrence of comorbidities, and as importantly a drastic reduction in mortality.

A significant decline in inflammatory rheumatic complications has been observed following the introduction of cART $[90,99]$. And of great interest and importance, a new group of rheumatic disorders has emerged covering the spectrum of systemic autoimmune and autoinflammatory diseases, posing new clinical challenges [90, 99] (Table 15.5). Currently, three diseases deserve special attention: avascular necrosis, osteoporosis, and immune reconstitution inflammatory syndrome.

Table 15.5 HIV and autoimmune/non-autoimmune diseases

\begin{tabular}{|l|l}
\hline Pre-cART & Post-cART \\
\hline Connective tissue diseases & Avascular necrosis \\
\hline DILS & Osteopenia/osteoporosis \\
\hline Myositis & IRIS \\
\hline Vasculitis & Sarcoidosis \\
\hline Arthritis & Graves' disease \\
\hline Reactive arthritis/psoriasis & Autoimmune hemolytic anemia \\
\hline HIV related & Autoimmune thrombocytopenia \\
& Uveítis \\
& Inflammatory bowel disease \\
& Psoriasis \\
\hline
\end{tabular}

\section{Changes in the Prevalence of Inflammatory Rheumatic Diseases}

Prior to the introduction of cART, reactive arthritis, psoriatic arthritis, and the painful articular syndrome were the most common rheumatic disorders observed in HIV-infected patients. However, after the introduction of cART, the incidence of these diseases decreased dramatically and new forms of rheumatic diseases appeared [99].

Calabrese et al. conducted a longitudinal cohort study and demonstrated post-cART a decline in ReA, PsA, and myositis [104]. Marquez et al. reported a rise in septic disorders and malignancies and a decline in spondyloarthritis [41]. DILS was also affected by cART. Basu et al. reported a decline in the incidence of DILS [86], but Mastroianni et al. reported opposite results [105]. As previously mentioned, Chen et al. reported that cART reduced the risk of acquiring DILS [91].

In contrast, Parperis et al. did not observe a higher risk of rheumatic diseases except avascular necrosis (AVN) and psoriasis [106]. Similar findings were reported by Yang et al. who showed that the prevalence of autoimmune arthritis among HIV infected patients was similar to that of the general population [107].

A recent study performed in the UK assessed 364 HIVpositive patients with musculoskeletal symptoms between January 2005 and December 2012. Majority of patients (85\%) referred had no evidence of an inflammatory rheumatic disease but instead were diagnosed with regional musculoskeletal pain, specific soft tissue disorders, chronic widespread pain or osteoarthritis. Among the remaining $15 \%$, most inflammatory diagnoses were not made more often than would be expected for the general population, except for spondyloarthritis [108].

There are few studies dealing with the incidence, prevalence, and chronology between rheumatic disorders associated with HIV infection and AIDS. Two large studies, one from Taiwan and the second from France, merit discussion $[90,109]$. In the first study, Yen et al. reported on the incidence of AIDS in a nationwide HIV/AIDS patient (PLWHA) cohort in Taiwan and compared it with the general population; standardized incidence rates (SIRs) were higher for incident Sjögren's syndrome, psoriasis, SLE, autoimmune hemolytic anemia (AHA), and uveitis. An interesting observation was the lower risk for development of AS despite a high prevalence of HLA-B27 in Taiwanese people (5\%). In contrast, PLWHA who received cART had higher SIRs for psoriasis, AHA, and uveitis, while those that did not receive cART had higher SIRs for Sjögren's syndrome, psoriasis, RA, SLE, and other autoimmune disorders. Lebrun et al. also conducted an epidemiologic study in a French nation-wide HIV cohort to estimate the prevalence of 26 inflammatory and autoimmune diseases 
(IADs) among patients living with HIV (PLHIV) in the cART era (from January 2000 to July 2013), and to describe their occurrence according to cART onset, the immune-virological status and hepatitis C virus (HCV) and/or hepatitis B virus coinfection. Results showed that several IADs including psoriasis, sarcoidosis, RA, AS, Grave's disease, AHA, immune thrombocytopenia, and chronic inflammatory bowel disease were the most prevalent diseases. Majority of patients $(59 \%)$ developed IAD after HIV infection with a mean delay of $10.6+-6.4$ years. In addition, patients developing IAD after the diagnosis of HIV infection, $572(70 \%)$ were on cART and 419 of them $(73 \%)$ had undetectable HIV viral load. Comparing data from Taiwan and French studies, some geographical variability in terms of IADs is observed, but both studies confirmed previous reports in the literature concerning the relationship between HIV/AIDS and rheumatic disorders.

\section{Immune Reconstitution Inflammatory Syndrome (IRIS)}

A resurgence of autoimmune disorders may occur following the introduction of cART due to the restoration of immune competence. This phenomenon known as IRIS is linked to a rapidly recovering immune system, and it appears directly related to an increase in $\mathrm{CD} 4+\mathrm{T}$ cells, CD8+ T cells, CD4+:CD8+ $\mathrm{T}$ cell ratio, and an increased cytokine levels [110] (Fig. 15.3). IRIS may develop in the following manners:

A. "Paradoxical IRIS"

In this subset, affected individuals develop symptoms and signs associated with a known opportunistic infection (OI) for which treatment is underway and exacerbate despite an earlier clinical response to therapy prior to ART.

B. "Unmasking IRIS"

Patients on this subset experience a new OI with a marked inflammatory component following initiation of ART. Recent reports, however, have defined all-new OI in the first 6 months of ART as cases of unmasking IRIS.

Several classification criteria for IRIS have been proposed, but none has been validated. The reported incidence of IRIS varies widely from $6.4 \%$ to $37.7 \%$ depending on the offending microorganism involved [111, 112].

IRIS is not only associated with a new infection or exacerbation of quiescent infections but also may occur as either new appearance or an exacerbation of a previously quiescent or occult autoimmune syndrome [41, 104]. Calabrese

Fig. 15.3 Pathogenesis IRIS

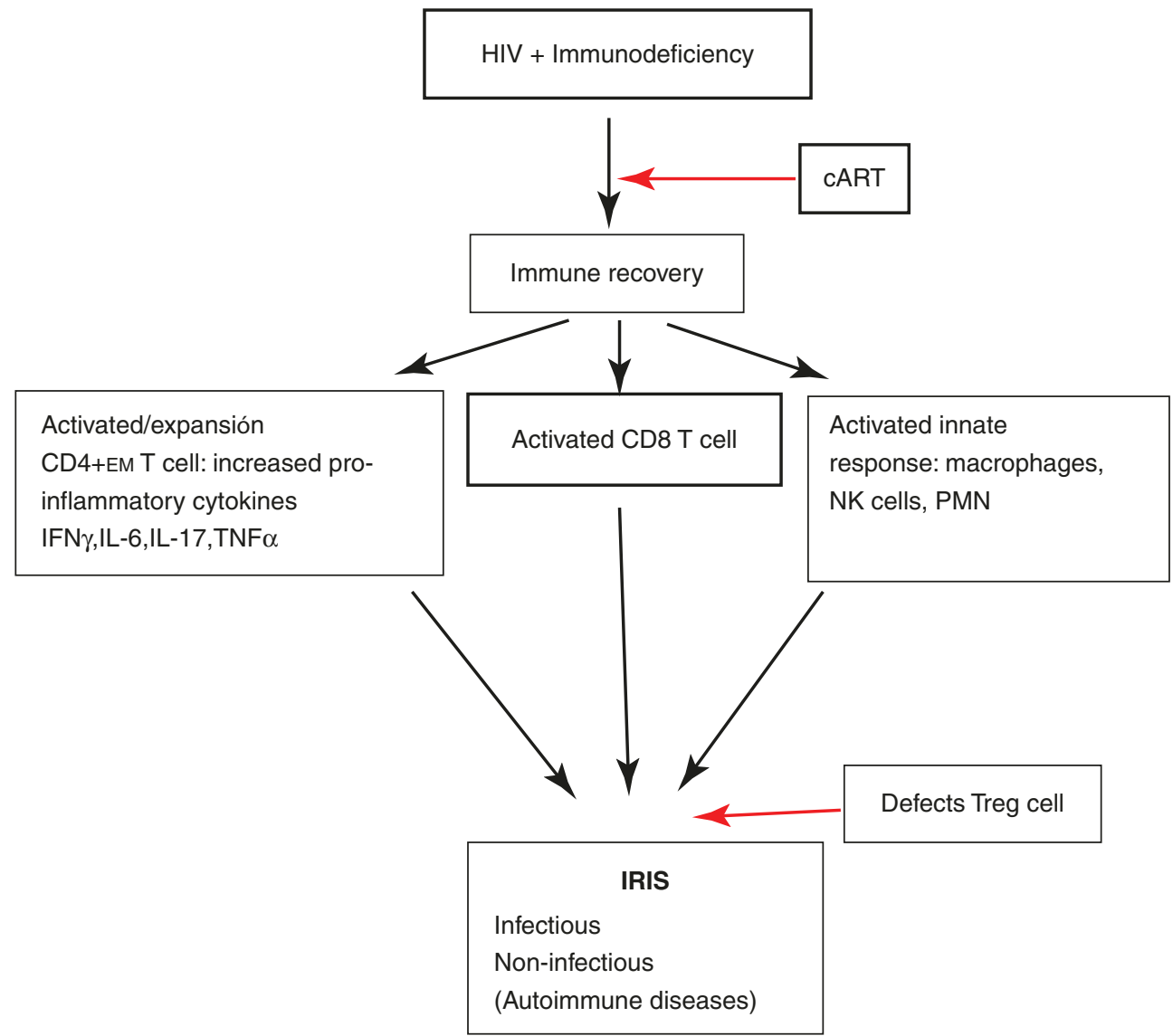


et al. conducted a prospective, longitudinal cohort study and described 32 cases associated with IRIS including sarcoidosis, RA, and SLE [104].

IRIS symptomatology may ensue days to months after ART begins, and most cases resolve spontaneously, but at times they can become life-threatening in severity, necessitating other therapeutic interventions. It is, however, usually not necessary to discontinue cART during this time. IRIS is generally self-limiting and should not require lifelong therapy $[41,104,111,112]$.

\section{Osteoporosis}

As the life span in HIV-infected individuals increases, new comorbid conditions develop, including osteopenia and osteoporosis, with an increase in the risk of bone fractures. It is estimated that 2 out of $3 \mathrm{HIV}$ infected individuals have osteopenia, and they also have 3.7 times more risk of developing osteoporosis than non-HIV infected individuals [113]. The estimated prevalence of osteoporosis in the HIV population is $15 \%$ and of osteopenia 52\% [114]. This decrease in bone density is between $2 \%$ and $6 \%$ during the first 2 years of cART $[115,116]$. The rate of fracture in the HIV population is between $30 \%$ and $70 \%$ compared with control nonHIV population [117-120].

In addition to the classic osteoporosis risk factors, other HIV-specific risk factors such as the same defined AIDS history, low CD4+ cell count, coinfection with hepatitis $\mathrm{C}$, and antiretroviral therapy may all contribute to the increased risk in osteoporosis [118, 119].

There is no specific guide for the management of HIV patients with decreased bone density, and HIV patients are not included in the list of patients at risk in the osteoporosis management guidelines [121]. However, there are two instruments, BMD or the application of FRAX, that can be used for the assessment of HIV patients with this problem, especially when treatment is considered in the presence of osteopenia. It should be kept in mind, however, that the FRAX has not been validated for the HIV-positive population [122].

Regarding therapy, in addition to adequate nutrition including calcium and vitamin D and modification of lifestyles, pharmacological therapy with bisphosphonates, alendronate, and zoledronic acid, have been shown to have a positive effect on BMD and tolerability similar to those found in the general population [123-126]. Other therapies have not been evaluated.

\section{Avascular Bone Necrosis (AVN)}

Osteonecrosis (AVN) is another complication associated with HIV infection, and when it affects hips or any other major joint might lead to severe disability. Its incidence has been estimated to be 10 times compared to the general population $[127,128]$. Prevalence also increases by almost $5 \%$ and is similar to the prevalence reported in patients at high risk for osteonecrosis in the context of a variety of underlying diseases [129].

Etiology of this complication is poorly understood, and little is known about potential risk factors in HIV patients. Use of glucocorticoids and hyperlipidemia contribute to osteonecrosis seen in HIV patients, but further studies are needed to fully characterize other potential risk factors for this complication [130, 131].

\section{Approach to Therapy of Rheumatic Disorders in HIV-Infected Patients}

The introduction of cART has had a profound effect on morbidity and survival in HIV-infected patients and the converse is also correct, HIV infection has also impacted a great deal on the natural history and therapeutic intervention of autoimmune diseases due to the presence of the underlying immunosuppression state and that complications can occur when immunosuppressive drugs or biologic agents are administered because they may lead to serious complications including infections [132].

Treatment of autoimmune diseases (AIDs) is similar in HIV-positive and HIV-negative patients. A significant proportion of HIV-associated AIDs including inflammatory musculoskeletal involvement respond well to conventional therapy such as NSAIDs, narcotic drugs and DMARDs, but refractory cases may need the use of biological agents, especially TNF inhibitors [133]. The use of these agents may represent a challenge, especially in patients with co-existent hepatitis infection, but published reports indicate that in the presence of stable CD4+ T cell counts and low viral loads their use can be both safe and efficacious. When considering immune suppressive therapy, it is important to keep in mind that CD4+ T cells are necessary in the control of intracellular and extracellular bacteria, parasites, and viruses, and the presence of TNF is needed and useful for controlling infection, and its increase favors replication of viral particles.

Rates of serious infections in HIV-infected patients treated with TNF- $\alpha$ inhibitors for concomitant AIDs are comparable to those observed in RA patients receiving TNF- $\alpha$ inhibitors [134].

At present, biologic agents and other DMARDs (including methotrexate, leflunomide, mycophenolate mofetil, azathioprine, cyclophosphamide, and cyclosporine) are recommended when patients have CD4+ T cell counts above 200 cells $/ \mathrm{mm} 3$ and HIV viral activity completely suppressed $[108,135,136]$. Glucocorticoids, hydroxychloroquine, and sulfasalazine have been shown to be safe and well-tolerated [96]. Currently, however, there are no studies of good quality on the use of biologic therapy to treat inflammatory disorders in HIV-infected individuals; therefore, we cannot conclude on efficacy and safety of biologic therapies in HIV-infected populations [137]. 


\section{Prophylaxis of Opportunistic Infections While on Immunosuppressive Therapy}

HIV patients on immunosuppressive therapy have an increased risk of infection reactivation. Close attention to the association between tuberculosis, varicella zoster, and opportunistic infections such as Pneumocystis jirovecii (PJ) should be kept in mind [135, 138]. Patients should be screened for HIV viral load, HBV, HCV, TB, and other infections according to endemic geography [139].

There are no guidelines with regard to the use of synthetic disease-modifying anti-rheumatic drugs (sDMARDs) and biologics in patients with a history of hepatitis B and hepatitis $\mathrm{C}$ infections. With regard to $\mathrm{PJ}$, there are no consensus guidelines for the prophylaxis of PCP in connective tissue diseases [140].

Prophylaxis for TB is recommended and it should follow the CDC guidelines. It is recommended to screen for latent TB prior to initiating chronic therapy with glucocorticoids, and chemoprophylaxis with either isoniazid (INH) for 9 months or rifampicin combined with INH for 3 months should be initiated in the presence of latent TB infection (LTBI) [141, 142].

\section{Conclusion}

Autoimmune and other inflammatory rheumatic disorders can occur in patients with HIV infection in the presence of poor or good immune-virological control under cART. Some AIDs are more prevalent according to cART and the cohort studied. In general, AIDs appear following diagnosis of HIV infection and also under cART, and clinical manifestations observed in the HIV population are similar to those seen in the general population. Glucocorticoids and other immunosuppressive agents seem to be effective and well-tolerated, but prophylaxis of infection is very important. Comorbidities such as osteoporosis and AVN appear as a consequence of the aging of the HIV-infected population and appropriate preventive measures should be taken. While the pathophysiology of HIV-related autoimmune rheumatic diseases is not well understood, the intricate enigma of this association merits further investigation.

\section{References}

1. Morens DM, Folkers GK, Fauci AS. Emerging infections: a perpetual challenge. Lancet Infect Dis. 2008;8:710-9.

2. Morens DM, Fauci AS. Emerging infectious diseases: threats to human health and global stability. PLoS Pathog. 2013;9:e1003467.

3. Machalaba CM, Karesh WB. Emerging infectious disease risk: shared drivers with environmental change. Rev Sci Tech. 2017;36:435-44.
4. Chabas H, Lion S, Nicot A, et al. Evolutionary emergence of infectious diseases in heterogeneous host populations. PLoS Biol. 2018;24:e2006738.

5. Morse SS. Factors and determinants of disease emergence. Rev Sci Tech. 2004;23:443-51.

6. van Boheemen S, de Graaf M, Lauber C, et al. Genome characterization of a newly discovered coronavirus associated with acute respiratory distress syndrome in humans. MBio. 2012;3:e00473-12.

7. Zanotto PMA, Leite LCC. The challenges imposed by dengue, zika, and chikungunya to Brazil. Front Immunol. 2018;9:1964. https://doi.org/10.3389/fimmu.2018.01964.

8. Jaffe HW, Bregman DJ, Selik RM. Acquired immune deficiency syndrome in the United States: the first 1,000 cases. J Infect Dis. 1983;148:339-45.

9. Singh S, Song R, Johnson AS, et al. HIV incidence, prevalence, and undiagnosed infections in U.S. men who have sex with men. Ann Intern Med. 2018;168:685-94.

10. Hess KL, Hu X, Lansky A, et al. Lifetime risk of a diagnosis of HIV infection in the United States. Ann Epidemiol. 2017;27:238-43.

11. Fauci AS, Folkers GK. The world must build on three decades of scientific advances to enable a new generation to live free of HIV/ AIDS. Health Aff (Millwood). 2012;31:1529-36.

12. Moir S, Wook Chun T, Fauci A. Pathogenic mechanisms of HIV disease. Annu Rev Pathol. 2011;6:223-48.

13. Paiardini M, Müller-Trutwin M. HIV-associated chronic immune activation. Immunol Rev. 2013;254:78-101.

14. Valverde-Villegas JM, Cotta Matte MC, Marília de Medeiros R, Bogo Chies J. New insights about Treg and Th17 cells in HIV infection and disease progression. J Immunol Res. 2015;2015:647916:1-14.

15. Zandman-Goddard G, Shoenfeld Y. HIV and autoimmunity. Autoimmun Rev. 2002;1:329-37.

16. Stratton R, Slapak G, Mahungu T, Kinloch-de-Loes S. Autoimmunity and HIV. Curr Opin Infect Dis. 2009;22:49-56.

17. Massabki PS, Accetturi C, Nishie IA, da Silva NP, Sato EI, Andrade LE. Clinical implications of autoantibodies in HIV infection. AIDS. 1997;11:1845-50.

18. Russo S, Lopalco L. Is autoimmunity a component of natural immunity to HIV? Curr HIV Res. 2006;4:177-90.

19. UNAIDS. Fact sheet-latest statistics on the status of the AIDS epidemic 2016. http://www.unaids.org/en/resources/fact-sheet. Access 23 Sept 2017.

20. CDC (2014). Laboratory testing for the diagnosis of HIV infection: updated recommendations.

21. Hentzien M, Dramé M, Allavena C, Jacomet C, Valantin M-A, Cabié A, et al. Impact of age-related comorbidities on five-year overall mortality among elderly HIV-infected patients in the late HAART era-role of chronic renal disease. J Nutr Health Aging. 2016;20:408-14.

22. Cuzin L, Katlama C, Cotte L, et al. Aging with HIV: do comorbidities and polymedication drive treatment optimization? HIV Med. 2017;18(6):395-401.

23. Lordache L, Launay O, Bouchaud O, Jeantils V, et al. Autoimmune diseases in HIV-infected patients: 52 cases and literature review. Autoimmunity Rev. 2014;13:850-7.

24. Winchester R, Bernstein DH, Fisher HD, et al. The co-occurrence of Reiter's syndrome and acquired immunodeficiency. Ann Intern Med. 1987;106:19-26.

25. Espinoza LR, Aguilar JL, Berman A, et al. Rheumatic manifestation associated with human immunodeficiency virus infection. Arthritis Rheum. 1989;32:1615-22.

26. Berman A, Espinoza LR, Diaz JD, et al. Rheumatic manifestations of human immunodeficiency virus infection. Am J Med. 1988;85:59-64. 
27. Berman A, Reboredo G, Spindler A, et al. Rheumatic manifestations in populations at risk for HIV infection: the added effect of HIV. J Rheumatol. 1991;18:1564-7.

28. Biviji AA, Paiement GD, Steinbach LS. Musculoskeletal manifestations of human immunodeficiency virus infection. J Am Acad Orthop Surg. 2002;10:312-20.

29. Rogeaux O, Fassin D, Gentilini M. Prevalence of rheumatic manifestations in human immunodeficiency virus infection. Ann Intern Med. 1993;144:443-8.

30. Hochberg MC, Fox R, Nelson KE, Saah A. HIV infection is not associated with Reiter's syndrome: data from the Johns Hopkins Multicenter AIDS Cohort Study. AIDS. 1990;4:1149-51.

31. Fox C, Walke-Bone K. Evolving spectrum of HIV-associated rheumatic syndromes. Best Pract Res Clin Rheumatol. 2015;29:244-58.

32. Pouchot J, Simonpoli AM, Bortolotti V, et al. Painful articular syndrome and human immunodeficiency virus infection. Arch Intern Med. 1992;152:646,649.

33. Ekwom PE, Oyoo GO, Amayo EO, Muriithi IM. Prevalence and characteristics of articular manifestations in human immunodeficiency virus infection. East Afr Med J. 2010;87:408-14.

34. Ouédraogo DD, Ntsiba $\mathrm{H}$, et al. Clinical spectrum of rheumatologic diseases in a department of rheumatology in Ouagadougou (Burkina Faso). Clin Rheumatol. 2014;33:385-9.

35. Chiowchanwisawakit P, Koolvisoot A, Ratanasuwan W, Suwanagool S. Prevalence of rheumatic disease in HIV-infected Thai patients. J Med Assoc Thailand. 2005;88:1775-81.

36. Zhang X, Li H, Li T, Zhang F, Han Y. Distinctive rheumatic manifestations in 98 patients with Human Immunodeficiency Virus infection in China. J Rheumatol. 2007;34:1760-4.

37. Reveille JD. The changing spectrum of rheumatic disease in human immunodeficiency virus infection. Semin Arthritis Rheum. 2000;30:147-66.

38. Muñoz Fernandez S, Cardenal A, Balsa A, et al. Rheumatic manifestations in 556 patients with human immunodeficiency virus infection. Sem Arth Rheum. 1991;21:30-9.

39. Medina-Rodriguez F, Guzman C, Jara LJ, et al. Rheumatic manifestations in human immunodeficiency virus-positive and negative individuals: a study of 2 populations with similar risk factors. J Rheumatol. 1993;20:1880-4.

40. Buskila D, Gladman DD, Langevitz P, et al. Rheumatologic manifestations of infection with the human immunodeficiency virus (HIV). Clin Exp Rheum. 1990;8:567-73.

41. Marquez J, Restrepo CS, Candia L, Berman A, Espinoza LR. Human immunodeficiency virus-associated rheumatic disorders in the HAART era. J Rheumatol. 2004;31:741-6.

42. Calabrese LH, Kelley DM, Myers A, et al. Rheumatic symptoms and human immunodeficiency virus infection. The influence of clinical and laboratory variables in a longitudinal cohort study. Arthritis Rheum. 1991;34:257-63.

43. Bileckot R, Mouaya A, Makuwa M. Prevalence and clinical presentations of arthritis in HIV positive patients seen at a rheumatology department in Congo-Brazzaville. Rev Rhum Engl Ed. 1998;65:549-54.

44. Blanche P, Taelman H, Saraux A, et al. Acute arthritis and human immunodeficiency virus infection in Rwanda. J Rheumatol. 1993;20:2123-7.

45. Stein CM, Davis P. Arthritis associated with HIV infection in Zimbabwe. J Rheumatol. 1996;23:506-11.

46. Clark MR, Solinger AM, Hochberg MC. Human immunodeficiency virus infection is not associated with Reiter's syndrome. Rheum Dis Clin N Am. 1992;18:267-76.

47. Casado E, Olivé A, Holgado S, et al. Musculoskeletal manifestations patients positive for immunodeficiency virus: correlation with CD4 count. J Rheumatol. 2001;21:81-3.
48. Monteagudo I, Rivera J, López-Longo J, et al. AIDS and rheumatic manifestations in patients addicted to drugs. An analysis of 106 cases. J Rheumatol. 1991;18:1038-41.

49. Mijiyawa M, Oniankitan O, Khan MA. Spondyloarthropathies in sub-Saharan Africa. Curr Opin Rheumatol. 2000;12:281-6.

50. Rachid B, Zorkany B, Youseif E, Tikly M. Early diagnosis and treatment of ankylosing spondylitis in Africa and the Middle East. Clin Rheumatol. 2012;31:1633-9.

51. López-Larrea C, Njobvu PD, Gónzales S, Blanco-Gelaz MA, Martínez-Borra J, López-Vásquez A. The HLA-B*5703 allele confers susceptibility to the development of spondylarthropathies in Zambian human immunodeficiency virus-infected patients with slow progression to acquired immunodeficiency syndrome. Arthritis Rheum. 2005;52:275-9.

52. Solinger AM, Hess EV. Rheumatic diseases and AIDS-is the association real? J Rheumatol. 1993;20:678-83.

53. Espinoza LR, Berman A, Vasey F, Cahalin C, Nelson R. Psoriatic arthritis and acquired immunodeficiency syndrome. Arthritis Rheum. 1988;31:1034-40.

54. Morar N, Willis-Owen SA, Maurer T, Bunker CB. HIV-associated psoriasis: pathogenesis, clinical features, and management. Lancet Infect Dis. 2010;10:470-8.

55. Tikly M, Njobvu P, McGill P. Spondyloarthritis in Sub-Saharan Africa. Curr Rheumatol Rep. 2014;16:421-5.

56. Ouédraogo DD, Meyer O. Psoriatic arthritis in Sub-Saharan Africa. Joint Bone Spine. 2012;79:17-9.

57. Dean LE, Jones GT, Macdonald AG, Dowham C, Sturrock RD, MacFarlane GJ. Global prevalence of ankylosing spondylitis. Rheumatology (Oxford). 2014;53:650-7.

58. Allsopp CE, Harding RM, Taylor C, et al. Interethnic genetic differentiation in Africa: HLA class I antigens in the Gambia. Am J Hum Genet. 1992;50:411-21.

59. Kalidi I, Fofana Y, Rahly AA, et al. Study of HLA antigens in a population of Mali (West Africa). Tissue Antigens. 1988;31:98-102.

60. Cunha BM, Mota LM, Pileggi GS, Safe IP, Lacerda MV. HIV/AIDS and rheumatoid arthritis. Autoimmun Rev. 2015;14:396-400.

61. Jackson S, Tarkowski A, Collins JE, Dawson LM, Schrohenloher $\mathrm{RE}$, Kotler DP, et al. Occurrence of polymeric IgA1 rheumatoid factor in the acquired immune deficiency syndrome. J Clin Immunol. 1988;8:390-6.

62. Procaccia S, Blasio R, Villa P, Lazzarin A, Bonacina C, Novati R, et al. Rheumatoid factors and circulating immune complexes in HIV-infected individuals. AIDS. 1991;5:1441-6.

63. du Toit R, Whitelaw D, Taljaard JJ, du Plessis L, Esser M. Lack of specificity of anticyclic citrullinated peptide antibodies in advanced human immunodeficiency virus infection. J Rheumatol. 2011;38:1055-60.

64. Gevorkian G, Soler C, Viveros M, Padilla A, Govezensky T, Larralde C. Serologic reactivity of a synthetic peptide from human immunodeficiency virus type $1 \mathrm{gp} 41$ with sera from a Mexican population. Clin Diagn Lab Immunol. 1996;3:651-3.

65. Li YC, Yang F, Ji XY, Fang ZJ, Liu J, Wang Y. False human immunodeficiency virus test results associated with rheumatoid factors in rheumatoid arthritis. Chin Med Sci J. 2014;29:103-6.

66. Azeroual A, Harmouche H, Benjilali L, Mezalek ZT, Adnaoui M, Aouni M, et al. Rheumatoid arthritis associated to HIV infection. Eur J Intern Med. 2008;19:e34-5.

67. Tarr G, Makda M, Musenge E, Tikly M. Effect of human immunodeficiency virus infection on disease activity in rheumatoid arthritis: a retrospective study in South Africans. J Rheumatol. 2014;41:1645-9.

68. Kerr LD, Spiera $H$. The coexistence of active classic rheumatoid arthritis and AIDS. J Rheumatol. 1991;18:1739-40. 
69. Ornstein MH, Kerr LD, Spiera H. A reexamination of the relationship between active rheumatoid arthritis and the acquired immunodeficiency syndrome. Arthritis Rheum. 1995;38:1701-6.

70. Gould T, Tikly M. Systemic lupus erythematosus in a patient with human immunodeficiency virus infection - challenges in diagnosis and management. Clin Rheumatol. 2004;23:166-9.

71. Carugati M, Franzzeti M, Torre A, Giorgi R, et al. Systemic lupus erythematosus and HIV infection: a whimsical relationship. Reports of two cases and review of the literature. Clin Rheumatol. 2013;32:1399-405.

72. Gul A, Inanc M, Yilmaz G, et al. Antibodies reactive with HIV-1 antigen in systemic lupus erythematosus. Lupus. 1996;5:120-2.

73. Molina JF, Citera G, Rosier D, Cuellar ML, Espinoza LR. Coexistence of human immunodeficiency virus infection and systemic lupus erythematosus. J Rheumatol. 1995;22:347-50.

74. Byrd VM, Sergent JS. Suppression of systemic lupus erythematosus by the human immunodeficiency virus. J Rheumatol. 1996;7:1295-6.

75. Mody GM, Patel N, Budhoo A, Dubula T. Concomitant systemic lupus erythematosus and HIV: case series and literature review. Semin Arthritis Rheum. 2014;44:186-94.

76. Bonsignori M, Wiehe K, Grimm SK, et al. An autoreactive antibody from an SLE/HIV-1 individual broadly neutralizes HIV. J Clin Invest. 2014;124:1835-43.

77. Sekigawa I, Lee S, Kaneko H, Lida N, Hashimoto H, et al. The possible role of interleukin-16 in the low incidence of HIV infection in patients with systemic lupus erythematosus. Lupus. 2000;9:155-7.

78. Two A, Kim So J, Paravar T. Discoid lupus and human immunodeficiency virus: a retrospective chart review to determine the prevalence and progression of co-occurrence of these conditions at a single academic center. Indian J Dermatol. 2017;62:226.

79. Leder AN, Flansbaum B, Zandman-Goddard G, Asherson R, Shoenfeld Y. Antiphospholipid syndrome induced by HIV. Lupus. 2001;10:370-4.

80. Mosquera JA, Ojea R, Navarro C. HIV infection associated with scleroderma: report of two new case. J Clin Pathol. 2010;63:852-3

81. Zicdar S, Grover C, Kubba S, Yadav A, Sahni V, et al. An uncommon cause of scleroderma. Scand J Rheumatol. 2005;343:242-5.

82. Okong'o LO, Webb K, Scott C. HIV-associated juvenile systemic sclerosis: a case report. Semin Arthritis Rheum. 2015;44:411-6.

83. Gresh JP, Aguilar JL, Espinoza LR. Human immunodeficiency virus (HIV) infection-associated dermatomyositis. J Rheumatol. 1989;16:1397-8.

84. Johnson RW, Williams FM, Kazi S, Dimachkie MM, Reveille JD. Human immunodeficiency virus-associated polymyositis: a longitudinal study of outcome. Arthritis Rheum. 2003; 15(49):172-8

85. Itescu S, Winchester R. Diffuse infiltrative lymphocytosis syndrome: a disorder occurring in human immunodeficiency virus-1 infection that may present as a sicca syndrome. Rheum Dis Clin N Am. 1992;18:683-97.

86. Williams F, Cohen P, Jumshyd J, Reveille J. Prevalence of the Diffuse Infiltrative Lymphocytosis syndrome among human immunodeficiency virus type1-positive outpatients. Arthritis Rheum. 1998;41:863-8.

87. Basu D, Williams F, Ahn CH, Reveille J. Changing spectrum of the diffuse infiltrative lymphocytosis syndrome. Arthritis Care Res. 2006;55:466-72.

88. Ghrenassia E, Martis N, Boyer J, Burel-Vandenbos F, Mekinian A, Coppo P. The diffuse infiltrative lymphocytosis syndrome (DILS). A comprehensive review. J Autoimmun. 2015;59:19-25.

89. Panayiotakopoulos GD, Aroni K, Kyriaki D, Paikos S, Vouyioukas $\mathrm{N}$, et al. Paucity of Sjogren-like syndrome in a cohort of HIV1-positive patients in the HAART era. Part II. Rheumatology. 2003;42:1164-7.
90. Yen Y-F, Chuang P-H, Jen I-A, Chen M. Incidence of autoimmune diseases in a nationwide HIV/AIDS patient cohort in Taiwan, 2000-2012. Ann Rheum Dis. 2017;76:661-5.

91. Chen M, Yen YF, Lan YC, Jen IA, Chuang PH, Lee CY, Lee Y, Lin YA. Risk of diffuse infiltrative lymphocytosis syndrome in HIVinfected patients: a nationwide population-based cohort study. J Acquir Immune Defic Syndr. 2018;79:158-63.

92. Otedo AE, Oyoo GO, Obondi JO, Otieno CF. Vasculitis in HIV:report of eight cases. East Afr Med J. 2005;82:656-9.

93. Calabrese L, Estes M, Yen-Lieberman B, Proffitt M, Tubbs R, Fishleder AJ, Levin KH. Systemic vasculitis in association with human immunodeficiency virus infection. Arthritis Rheumatol. 1989;32:569-76

94. Patel N, Patel N, Khan T, Patel N, Espinoza LR. HIV infection and clinical spectrum of associated vasculitides. Curr Opin Rep. 2011;13:506-12.

95. Patel N, Patel N, Espinoza L. HIV infection and rheumatic diseases: the changing spectrum of clinical enigma. Rheum Dis Clin N Am. 2009;35:139-61

96. Virot E, Duclos A, Adelaide L, Miailhes P, et al. Autoimmune diseases and HIV infection. A cross-sectional study. Medicine. 2017;96:e5769.

97. Fabris P, Tositti G, Giordani MT, et al. Prevalence and clinical significance of circulating cryoglobulins in HIV-positive patients with and without co-infection with hepatitis C virus. J Med Virol. 2003;69:339-43.

98. Kosmas N, Kantos A, Panayiota Kopoulos G, et al. Decreased prevalence of mixed cryoglobulinemia in the HAART era among HIVpositive, HCV-negative patients. J Med Virol. 2006;78:1257-61.

99. Nguyen BY, Reveille JD. Rheumatic manifestations associated with HIV in the highly active antiretroviral therapy era. Curr Opin Rheumatol. 2009;21:404-10.

100. Ventura G, Gasparini G, Lucia MB, Tumbarello M, Tacconelli E, Caldarola $\mathrm{G}$, et al. Osteoarticular bacterial infections are rare in HIV-infected patients. Acta Orthop Scand. 1997;60:554-8.

101. Jellis J. Orthopaedic surgery and HIV disease in Africa. Int Orthop. 1996;20:253-6.

102. Vassilopoulos D, Chalasani P, Jurado RL, Workowski K, Agudelo CA. Musculoskeletal infections in patients with human immunodeficiency virus infection. Medicine (Baltimore). 1997;76:284-9.

103. Yao Q, Frank M, Glynn M, Altman RD. Rheumatic manifestations in HIV-1 infected in-patients and literature review. Clin Exp Rheumatol. 2008;26:799-80.

104. Calabrese L, Kirchner E, Shrestha R. Rheumatic complications of human immunodeficiency virus infection in the era of highly active antiretroviral therapy: emergence of a new syndrome of immune reconstitution and changing patterns of disease. Semin Arthritis Rheum. 2005;35:166-74.

105. Mastroianni A. Emergence of Sjogren's syndrome in AIDS patients during highly active antiretroviral therapy. AIDS. 2004;18:1349-52.

106. Parperis K, Abdulqader $\mathrm{Y}$, Myers R, Bhattarai B, Al-Ani M. Rheumatic diseases in HIV-infected patients in the postantiretroviral therapy era: a tertiary care center experience. Clin Rheumatol. 2019;38(1):71-6. https://doi.org/10.1007/ s10067-018-4089-z.

107. Yang JJ, Tsai MS, Sun HY, Hsieh SM, Chen MY, Sheng WH, Chang SC. Autoimmune diseases-related arthritis in HIV-infected patients in the era of highly active antiretroviral therapy. J Microbiol Immunol Infect. 2015;48:130-6.

108. Walker-Bone K, Doherty E, Sanyal K, Churchill D. Assessment and management of musculoskeletal disorders among patients living with HIV. Rheumatology. 2017;56:1648-61.

109. Lebrun D, Hentzien M, Cuzin L, Rey D, et al. Epidemiology of autoimmune and inflammatory diseases in a French Nationwide HIV cohort. AIDS. 2017;31:2159-66. 
110. Martin-Blondel G, Mars LT, Liblau RS. Pathogenesis of the immune reconstitution inflammatory syndrome in HIV-infected patients. Curr Opin Infect Dis. 2012;25:312-20.

111. Walker NF, Scriven J, Meintjes G, Wilkinson RJ. Immune reconstitution inflammatory syndrome in HIV-infected patients. HIV AIDS (Auckl). 2015;7:49-64.

112. Naidoo K, Yende-Zuma N, Padayatachi N, et al. Immune reconstitution inflammatory syndrome following antiretroviral therapy initiation in tuberculosis patients: findings from the SAPiT trial. Ann Intern Med. 2012;157:313-24.

113. Brown TT, Qaqish RB. Antiretroviral therapy and the prevalence of osteopenia and osteoporosis: a meta-analytic review. AIDS. 2006;20:2165-74.

114. Paccou J, Viget N, Legrout-Gerot I, et al. Bone loss in patients with HIV infection. Joint Bone Spine. 2009;76:637-41.

115. McComsey GA, Tebas P, Shane E, et al. Bone disease in HIV infection: a practical review and recommendations for HIV care providers. Clin Infect Dis. 2010;51:937-46.

116. Yin MT, Overton ET. Increasing clarity on bone loss associated with antiretroviral initiation. J Infect Dis. 2011;203(12): 1705-7.

117. Dao C, Young B, Buchacz K, et al. Higher and increasing rates of fracture among HIV-infected persons in the HIV outpatient study (HOPS) compared to the general US population, 1994 to 2008 [abstract 128]. In: Program and abstracts of the 17th Conference on Retroviruses and Opportunistic Infections, 18 February 2010, San Francisco, CA.

118. Yin MT, Shi Q, Hoover DR, et al. Fracture incidence in HIVinfected women: results from the Women's Interagency HIV Study. AIDS. 2010;24:2679-86.

119. Yong MK, Elliott JH, Woolley IJ, Hoy JF. Low CD4 count is associated with an increased risk of fragility fracture in HIV-infected patients. J Acquir Immune Defic Syndr. 2011;57:205-10.

120. Collin F, Duval X, Le Moing V, et al. Ten-year incidence and risk factors of bone fractures in a cohort of treated HIV1-infected adults. AIDS. 2009;23:1021-4.

121. Foundation NO. Clinician's guide to prevention and treatment of osteoporosis. Washington, DC: National Osteoporosis Foundation; 2010.

122. Lundgren JD, Battegay M, Behrens G, et al. European AIDS Clinical Society (EACS) guidelines on the prevention and management of metabolic diseases in HIV. HIV Med. 2008;9: $72-81$.

123. McConse GA, Kendall MA, Tebas P, et al. Alendronate with calcium and vitamin D supplementation is safe and effective for the treatment of decreased bone mineral density in HIV. AIDS. 2007;21:2473-82.

124. Mondy K, Powderly WG, Claxton SA, et al. Alendronate, vitamin $\mathrm{D}$, and calcium for the treatment of osteopenia/osteoporosis associated with HIV infection. J Acquir Immune Defic Syndr. 2005;38:426-31.

125. Bolland MJ, Grey AB, Horne AM, et al. Annual zoledronate increases bone density in highly active antiretroantiviral therapy-treated human immunodeficiency virus-infected men: a randomized controlled trial. J Clin Endocrinol Metab. 2007;92:1283-8.
126. Huang J, Meixner L, Fernández S, McCutchan JA. A doubleblinded, randomized controlled trial of zoledronate therapy for HIV-associated osteopenia and osteoporosis. AIDS. 2009;23:51-7.

127. Brown P, Crane L. Avascular necrosis of bone in patients with human immunodeficiency virus infection: report of 6 cases and review of the literature. Clin Infect Dis. 2001;32:1221-6.

128. Calza L, Manfredi R, Mastroianni A, Chiodo F. Osteonecrosis and highly active antiretroviral therapy during HIV infection: report of a series and literature review. AIDS Patient Care STDs. 2001;15:385-9.

129. Assouline-Dayan Y, Chang C, Greenspan A, Shoenfeld Y, Gershwin ME. Pathogenesis and natural history of osteonecrosis. Semin Arthritis Rheum. 2002;32:94-124.

130. Glesby MJ, Hoover DR, Vaamonde CM. Osteonecrosis in patients infected with human immunodeficiency virus: a case-control study. J Infect Dis. 2001;184:519-23.

131. Grdmintas L, Solomon DH. HIV and its effects on bone: a primer for rheumatologists. Curr Opin Rheumatol. 2012;24:567-75.

132. Maganti R, Reveille J, Williams R. Therapy Insight: the changing spectrum of rheumatic disease in HIV infection. Nat Clin Pract Rheum. 2008;4:428-38.

133. Gallitano S, McDermott L, Brar K, Lowenstein E. Use of tumor necrosis factor (TNF) inhibitors in patients with HIV/AIDS. J Am Acad Dermatol. 2016;74:974-80.

134. Wangsiricharoen S, Ligon C, Gedmintas L, Dehrab A, Calabrese $\mathrm{L}$, et al. The rates of serious infections in HIV-infected patients who received tumor necrosis factor (TNF)- $\alpha$ inhibitor therapy for concomitant autoimmune diseases. Arthritis Care Res. 2017;69:449-52.

135. Adizie T, Moots RJ, Hodkinson B, French N, Adebajo AO. Inflammatory arthritis in HIV positive patients: a practical guide. BMC Infect Dis. 2016;16:100.

136. Packham J, Arkell P, Sheeran T, et al. Patient experiences, attitudes and expectations towards receiving information about anti-TNF medication: a quantitative study. Clin Rheumatol. 2017;36:2595-600.

137. Fink DL, Hedley L, Miller RF. Systematic review of the efficacy and safety of biological therapy for inflammatory conditions in HIV-infected individuals. Int J STD AIDS. 2017;28:110-9.

138. Youssef J, Novosad SA, Winthrop KL. Infection risk and safety of corticosteroid use. Rheum Dis Clin N Am. 2016;42:157-76.

139. Mosca M, Tani C, Aringer M, Bombardieri S, Boumpas D, et al. European League Against Rheumatism recommendations for monitoring patients with systemic lupus erythematosus in clinical practice and in observational studies. Ann Rheum Dis. 2010;69:1269-74.

140. Wolfe RM, Peacock JE Jr. Pneumocystis pneumonia and the rheumatologist: which patients are at risk and how can PCP be prevented? Curr Rheumatol Rep. 2017;19:35-44.

141. Singh JA, Furst DE, Bharat A, et al. 2012 update of the 2008 American College of Rheumatology recommendations for the use of disease-modifying antirheumatic drugs and biologic agents in the treatment of rheumatoid arthritis. Arthritis Care Res. 2012;64:625-39.

142. Botha-Scheepers SA, Sarembock B. Infections in the management of rheumatic diseases: an update. S Afr Med J. 2015;105:1076. 